\title{
Influence of Market Orientation on Absorptive Capacity: On the Bright and Dark Sides of Customer Participation in New Product Development-An Abstract
}

\author{
Todd Morgan, Sergey Anokhin, and Joakim Wincent
}

\begin{abstract}
Extant research suggests that open innovation may be a double-edged sword. On the positive side, it may help enhance new product development (NPD) efforts by bringing in required knowledge and resources. Conversely, it may increase a firm's dependence on customer input for the NPD process. We suggest that breadth versus depth of customer participation may be the key to enhancing a firm's learning efforts and in turn, NPD performance. In this study, we predict and find that market orientation positively influences a firm's absorptive capacity including the ability to acquire, transform, assimilate, and exploit external knowledge for commercial ends. We find that the influence of market orientation on absorptive capacity may either be enhanced by having customers participate in a greater number of activities throughout the development process (customer participation breadth) or diminished when customers are involved at deeper levels (customer participation depth). As we report that a firm's absorptive capacity capability is positively related to NPD performance and mediates the relationship between market orientation and NPD performance, the results suggest that there is both a bright side and dark side of customers participating in NPD activities and the exact involvement of customers is a critical decision. This has clear implications for the dialogues about customer involvement in industrial settings and management of industrial customer relationships.
\end{abstract}

\footnotetext{
T. Morgan $(\bowtie)$

University of Massachusetts Lowell, Lowell, MA, USA

e-mail: todd_morgan@uml.edu

S. Anokhin

Kent State University, Kent, OH, USA

e-mail: sanokhin@kent.edu

J. Wincent

Luleå University of Technology, Luleå, Sweden

Hanken School of Economics, Helsinki, Finland

e-mail: joakim.wincent@1tu.se
} 